\title{
Surface Integrity after Mechanical Hardening of Various Aluminium Alloys
}

\author{
Sebastjan Žagar - Janez Grum* \\ University of Ljubljana, Faculty of Mechanical Engineering, Slovenia
}

\begin{abstract}
The paper presents two types of aluminium alloys, EN AW 2007 and EN AW 6082, treated by shot peening in which the surfaces of the metals were subjected to cold deformation under different treatment conditions. For this purpose, S170 steel particles with a diameter of $0.5 \mathrm{~mm}$ and a hardness of $56 \mathrm{HRC}$ were used with different air pressures and mass flows, providing Almen intensity levels between $10 \mathrm{~A}$ and 28A. The treated surfaces were studied in terms of surface integrity at macro- and microscopic levels, and the surface roughness, microhardness profiles, and residual stresses of each treated surface layer were recorded. Research results reveal significant differences between the properties recorded in the surface integrity examination, which are based on the selected shot peening parameters. This means that these parameters substantially impact the surface conditions and the surface layer. The microscopic analysis confirmed that the sharpest treatment conditions result in surface deformations which may cause cracks and subsequently lead to the mechanical part's collapse.

(C2011 Journal of Mechanical Engineering. All rights reserved.
\end{abstract}

Keywords: shot peening, surface integrity, surface roughness, residual stresses, microhardness

\section{INTRODUCTION}

Due to numerous set-up parameters, shot peening is a very complicated process. By changing the parameters, a comparison of various treatment effects can be made based on Almen intensity measurements. The effects of the shot peening process can be influenced by modifying the following properties:

- Peening medium type,

- Available amount of the peening medium energy,

- Mass flow determining surface coverage,

- Angle of incidence of the peening medium,

- Nozzle distance,

- Shot peening exposure time.

The quality of the shot-peened surface strongly depends on the material type and properties, the type of previously performed treatments, and the depth of the hardened layer [1] to [4]. For practical reasons, the industry compares the efficacy of various shot peening conditions to Almen intensity, which classifies these conditions according to hardness level. This, however, does not allow a direct comparison of microstructural changes nor a comparison of microhardness profiles and residual stresses of the mechanical part [5]. Moreover, shot peening also affects surface microgeometry which is modified depending on the impact intensity of individual particles. Shot-peened surfaces are described in terms of standard surface roughness parameters [6] and [7].

Cold plastic deformation of the material's surface layer increases the density of dislocations, which in turn enhances the hardness of the material and causes residual stresses in the thin surface layer. Peening conditions that ensure a quality surface and an adequate fatigue strength of the material by using the particles' kinetic energy must, therefore, be selected. If shot peening parameters are too sharp, surface defects which undermine longterm hardness of materials in dynamic loading despite their enhanced hardness and greater residual stresses [8] and [9] may occur.

Herzog et al. [10] investigated the correlation between the material type, diameter, shot peening speed, and mass flow of the particles and hardness profiles and residual stresses in the surface layer of the 7020 aluminium alloy. As shot peening research parameters were modified, shot peening effects were determined by using Almen intensity. The results revealed that the size and profiles of the surface layer residual stresses influence the longevity of the material's dynamic hardness, i.e. fatigue strength. Additionally, this 
proved that in order to predict the desired residual stress profiles, a comparison between the shot peening parameters and Almen intensity will not suffice, as all parameters relevant to the process must always be included.

Guagliano [11] established a correlation between Almen intensity and different particle sizes and speeds for various materials under the same shot peening conditions. The induced residual stress profiles of the specimen surface layer after the shot peening process were determined by using the end elements method and were then compared with the experimental results. The research proved that by using the end elements method the residual stress profiles of the specimen surface layer can be very successfully predicted, with minor deviation, for different particle diameters $(0.5 \mathrm{~mm})$ and constant Almen intensity $(12 \mathrm{~A})$. The aim of the research was to offer users adequate guidance in selecting optimal shot peening conditions that guarantee the desired or required residual stress profiles.

Hong et al. [12] also used the end elements method to analyze the influence of individual shot peening parameters on the achieved residual stress profiles, such as the selection of various particle diameters and speeds while considering different angles of incidence. It was found that the particles reach the highest residual stress values at the angles of incidence between 90 and $75^{\circ}$. With the angles of incidence smaller than $75^{\circ}$, the same depths of the hardened layer are achieved with different residual stress profiles.

Kek et al. [13] present the research of a laser surface hardening process applied to the C45E steel with graphite absorber coating on specimen surfaces. The evaluation of the laser surface hardening process was performed by measuring the IR radiation from the interaction spot. The results confirmed a strong correlation between the IR radiation voltage signal and the dimensions of microstructural changes occuring in the laser surface hardening steel.

Trdan et al. [14] also investigated the optimum laser shock processing parameters for aluminium specimens in order to obtain the desired residual stress variation and improved corrosion resistance. The conducted experiments confirmed a characteristic influence of the first factor representing different pulse densities.
Potentiodynamic corrosion testing confirmed that the higher pulse density resulted in a stronger shift of pitting potential, which provided higher corrosion resistance.

Zupanc et al. [15] investigated the effect of surface hardening by shot peening on fatigue properties of high-strength aluminium alloy 7075T651. The obtained results show a favourable influence of SP treatment on fatigue properties as induced compressive residual stresses and hardened surface layer retarded the initiation of fatigue cracks.

\section{EXPERIMENTAL PART}

\subsection{Materials}

Shot peening experiments using hard particles were conducted on the 2007-T351 and 6082-T651 aluminium alloys with the aim of comparing different shot peening parameters that influence surface integrity.

The specimens were obtained by cutting a 40-millimeter diameter rod into 8-millimeter thick disks. The cutting was performed with a cutting wheel used in the preparation of metallographic specimens under mild conditions and by using a coolant.

The 2007-T351 aluminium alloy was first subjected to homogenization annealing at 495 ${ }^{\circ} \mathrm{C}$ and then hardened by natural ageing at room temperature. The chemical compositions of both alloys are given in Table 1. Apart from aluminium, the 2007 alloy also includes $3.3 \%$ to $4.6 \%$ copper, forming the first secondary phase $\mathrm{Al} 2 \mathrm{Cu}$, and magnesium and silicon, forming the second secondary phase $\mathrm{Mg} 2 \mathrm{Si}$. Both phases contribute to improving the alloy's mechanical properties.

The other aluminium alloy, 6082 T651, was first treated by the homogenization annealing process at $540{ }^{\circ} \mathrm{C}$ and subsequently hardened by artificial ageing at $160{ }^{\circ} \mathrm{C}$ for 10 hours. The amount of copper in the 6082 alloy is very low, but the secondary phase $\mathrm{Mg} 2 \mathrm{Si}$, formed by magnesium and silicon, enhances the solid solution after ageing. The standard-based mechanical properties of both aluminium alloys are given in Table 2. The 2007 alloy with the separate phases $\mathrm{A} 12 \mathrm{Cu}$ and $\mathrm{Mg} 2 \mathrm{Si}$ has greater 
Table 1. Chemical composition of the treated aluminium alloys

\begin{tabular}{|c|c|c|c|c|c|c|c|c|c|c|}
\hline \multirow{2}{*}{ Designation } & \multicolumn{10}{|c|}{ Element [\%wt] } \\
\cline { 2 - 13 } & $\mathrm{Si}$ & $\mathrm{Fe}$ & $\mathrm{Cu}$ & $\mathrm{Mn}$ & $\mathrm{Mg}$ & $\mathrm{Cr}$ & $\mathrm{Ni}$ & $\mathrm{Zn}$ & $\mathrm{Ti}$ & $\mathrm{Al}$ \\
\hline ENAW 2007 & 0.8 & 0.8 & $3.3-4.6$ & $0.5-1.0$ & $0.4-1.8$ & 0.1 & 0.2 & 0.8 & 0.2 & rest \\
\hline ENAW 6082 & $0.7-1.3$ & 0.5 & 0.1 & $0.4-1.0$ & $0.6-1.2$ & 0.25 & $/$ & 0.2 & 0.1 & rest \\
\hline
\end{tabular}

Table 2. Mechanical properties of the treated aluminium alloys

\begin{tabular}{|c|c|c|c|c|c|c|}
\hline Designation & State & $\begin{array}{c}\text { Chemical } \\
\text { designation }\end{array}$ & $\begin{array}{c}R m \\
{[\mathrm{MPa}]}\end{array}$ & $\begin{array}{c}R p_{0,2} \\
{[\mathrm{MPa}]}\end{array}$ & $\begin{array}{c}A \\
{[\%]}\end{array}$ & $\begin{array}{c}\text { Hardness } \\
{\left[\mathrm{HV}_{0.2}\right.}\end{array}$ \\
\hline ENAW 2007 & T351 & AlCu4PbMgMn & 370 & 240 & 9 & 118 \\
\hline ENAW 6082 & $\mathrm{T} 651$ & AlSi1MgMn & 310 & 260 & 13.5 & 89 \\
\hline
\end{tabular}

Table 3. Shot peening parameters of the treated aluminium specimens

\begin{tabular}{|c|c|c|c|c|c|}
\hline \multirow{3}{*}{ Alloy } & Specimen & $\begin{array}{c}\text { Working } \\
\text { pressure } p[\mathrm{bar}]\end{array}$ & $\begin{array}{c}\text { Mass flow } \dot{m} \\
{[\mathrm{~kg} / \mathrm{min}]}\end{array}$ & $\begin{array}{c}\text { Nozzle speed } v_{N} \\
{[\mathrm{~mm} / \mathrm{min}]}\end{array}$ & $\begin{array}{c}\text { Arc height } h \\
{[\mathrm{mmA}]}\end{array}$ \\
\hline \multirow{3}{*}{2007} & $\# 1$ & 1.6 & 1.0 & 1800 & 0.25 \\
\cline { 2 - 6 } & $\# 8$ & 1.6 & 1.5 & 2400 & 0.31 \\
\cline { 2 - 6 } & $\# 9$ & 4 & 1.6 & 2600 & 0.53 \\
\cline { 2 - 6 } & $\# 13$ & 8 & 1.5 & 2800 & 0.7 \\
\hline \multirow{3}{*}{6082} & $\# 3$ & 1.6 & 1.0 & 2800 & 0.25 \\
\cline { 2 - 6 } & $\# 7$ & 1.6 & 1.5 & 3000 & 0.31 \\
\cline { 2 - 6 } & $\# 12$ & 4 & 1.6 & 3200 & 0.53 \\
\hline
\end{tabular}

tensile strength and hardness than the 6082 alloy which yields a single separate phase, i.e. $\mathrm{Mg} 2 \mathrm{Si}$.

\subsection{Specimen Preparation}

Only the S170 steel balls with a diameter of $0.5 \mathrm{~mm}$ were used in shot peening surface treatment on all specimens. The process was performed on a number of specimens with different mass flows $(\dot{m})$, which was achieved by selecting various working air pressures $(p)$ determining particle travel speed and kinetic energy. These different air pressure values were also used to obtain different mass flows of the steel balls. Upon impact, the particles' kinetic energy causes plastic deformation of the specimen surface. The level of plastic deformation is determined through surface hardness modifications and the hardness profile of the thin surface layer. The changes in the hardness profile and residual stresses of the shot-peened layer depend on dislocation density after surface treatment. The treatment utilizing the particles' kinetic energy guarantees longer life cycle of mechanical parts, which depends on the density of the dislocations occurring after treatment.

The overlap of the indentations made by individual balls on the specimen surface is defined by the particle mass flow and travel speed. The shot-peening parameters for the 2007 and 6082 alloys are given in Table 3. Individual specimens of both alloys, which were treated under different conditions, are marked with numbers. The same conditions were applied to both alloys and only air pressure, particle mass flow, and nozzle speed values varied. Based on Almen values, it can be concluded that the first two specimens were subjected to very similar conditions, i.e. $10 \mathrm{~A}$ and $12 \mathrm{~A}$, while sharper conditions were applied to the remaining two, with a substantial deviation from mild conditions. $21 \mathrm{~A}$ and $28 \mathrm{~A}$ were selected as sharp shot-peening conditions. The results of the surface treatment can, therefore, be compared with the actual conditions or, alternatively, a comparison based on the Almen intensity test can be applied. 


\section{RESULTS AND DISCUSSION}

\subsection{Surface Roughness}

Surface roughness was determined in all specimens immediately after they were cut and after the surfaces were treated by shot peening. Surface roughness was measured in various directions according to cutting direction. The specimens were also measured for microhardness and residual stresses before and after treatment. In addition, a microstructural analysis of the material before and after shot peening was performed by using optical microscopy.

The arithmetic mean roughness $R_{a}$ of the surface profile and the mean roughness depth $R_{z}$ were chosen as the properties used to estimate the roughness of shot-peened specimens. In their studies, authors generally focus only on one of these when describing surface profile. In our research, however, both values were calculated in order to achieve a better view of the surface arch formation. The values $\left(R_{a}\right.$ and $\left.R_{z}\right)$ were determined based on the captured surface profile utilizing Taylor Hobson's Surtronic 3+ profile meter and their software, TalyProfile Lite 3.1.4.

The profiles of the shot-peened specimen surfaces were captured at a length of $L=8 \mathrm{~mm}$, with 10 repetitions, and recorded at different reference points, namely, in two directions at the specimen edge and in the specimen centre. The measuring positions and surface profile directions are indicated in Fig. 1. Eight measurements were performed at the edge of the shot-peened specimen, four of them longitudinally and four transversely. The remaining two measurements were obtained in the centre of the shot-peened specimen in both directions. Based on the ten surface profile records of a single specimen, both mean rougness values, $R_{a}$ and $R_{z}$, were calculated. To obtain surface roughness values under different shot-peening conditions, both mean values, $R_{a}$ and $R_{z}$, were calculated for the two aluminium alloys. The data on these two properties help to estimate the differences occuring in the surface layer before and after the shot peening of specimens under different shot-peening conditions. When comparing different measurement directions, deviations in surface roughness can only be found in untreated specimens, which is attributed to uneven cutting due to the pressure variation of the cutting wheel. The resulting abrasions are proportionally uneven, directed, big, and clearly visible.

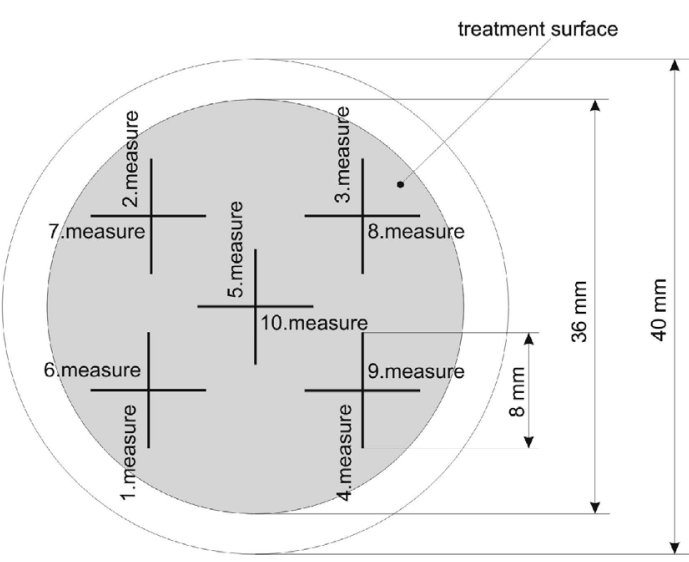

Fig. 1. Measuring positions in both treated aluminium alloys

After the surface was treated by shot peening using hard steel balls, its profile varied based on treatment conditions. The calculated values confirm this fact. The column diagrams representing the calculated arithmetic mean of surface roughnesses $\bar{R}_{a}$ and the mean values of profile depth $\bar{R}_{z}$ are shown in Figs. 2 and 3. The calculated values of both properties, $\bar{R}_{a}$ and $\bar{R}_{z}$, differentiate on the multiple level before as well as after specimen treatment.

After the surface treatment by shot peening, surface roughness increases with an increase in the working pressure, with constant mass flow and nozzle speed. The specimens treated at the same working pressure, i.e. $1.6 \mathrm{bar}$, but with different particle mass flows reveal no significant differences in the calculated surface roughness values. The results show that by increasing the particle mass flow from $1 \mathrm{~kg} / \mathrm{min}$ to $1.5 \mathrm{~kg} / \mathrm{min}$, while air pressure remains constant, surface roughness even slightly decreases, as expected. The lesser degree of roughness with greater mass flow is attributed to increased impact coverage of the treated surface. This means that a greater degree of overlap between individual arch formations and lesser surface roughness is achieved with increased particle mass flow. 


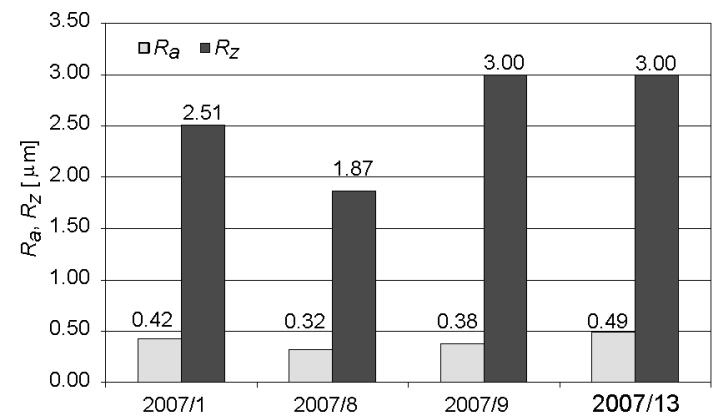

a)

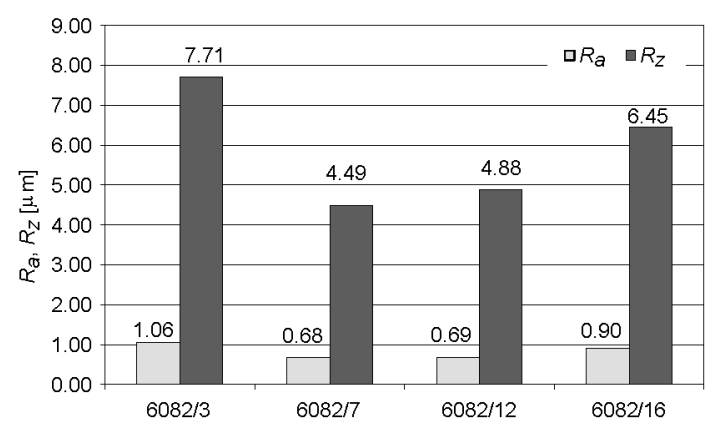

b)

Fig. 2. Surface roughness before treatment for both aluminium alloys; a) alloy 2007-T351, b) alloy 6082-T651

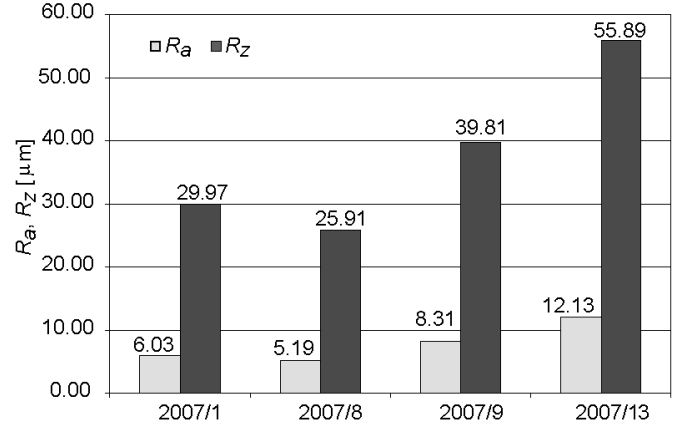

a)

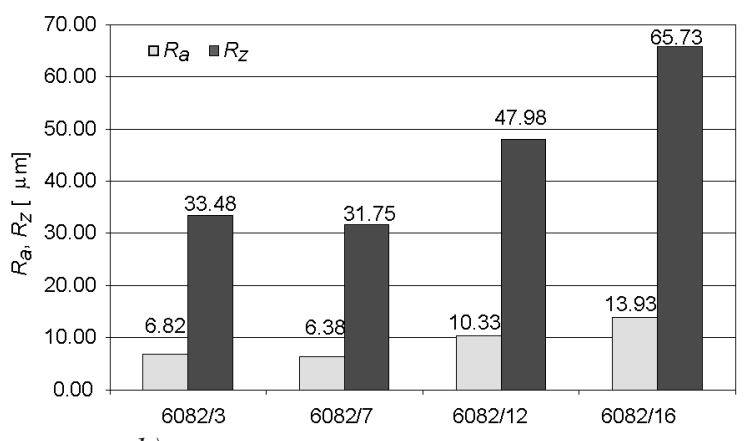

b)

Fig. 3. Surface roughness after treatment for both aluminium alloys; a) alloy 2007-T351, b) alloy 6082-T651

The specimens treated with higher working air pressures ( 4 bar and 8 bar) confirm that the particles' kinetic energy used for the shot peening treatment of the surface is greater and, with constant mass flow, contributes to increasing surface roughness profile. Surface roughness can be estimated based on the arch height and given in Almen intensity. The results reveal that roughness increased with an increase in Almen intensity. An increase in roughness of the shot-peened surfaces is characteristic of softer materials, including the selected aluminium alloys [16].

\subsection{Metallography of Treated Specimens}

Overlapping of individual arch formations generated by the particles impacting the specimen surface can be revealed through microanalysis. The depth of the formation in the surface layer of the treated specimens can be estimated from specimen cross-section. For this purpose, one fourth of the specimen was cut off and measured under the microscope. Macro images of specimen cross-sections, magnified 200 times, were recorded and a 500x microscopic analysis was performed.

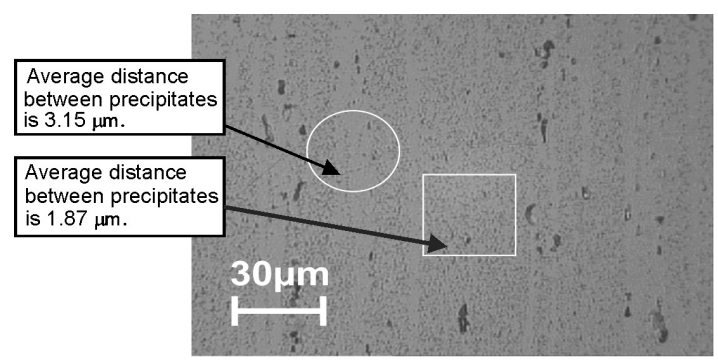

Fig. 4. Microstructure of the treated sample

Fig. 4 depicts the specimen microstructure before shot peening, consisting of a soft matrix and precipitates. The frame in Fig. 4 indicates an area of increased precipitate concentration and the 
encircled area is the area with a smaller precipitate concentration. The increased concentration of more solid precipitation influences the level of plastic deformation of the surface resulting in less surface roughness.

The surface after shot peening is represented by the macro images given in Figs. 5 and 6 , with clearly visible indentations made by individual particles. Specimen microstructures examined under magnitudes of 200x and 1000x after the shot peening of the ENAW 2007 and ENAW 6082 aluminium alloys are shown in Figs. 5 and 6 , respectively. The microstructure is visible due to extrusion, along with the fine distribution of the crystallized phases. The cross-section of the thin surface layers shown in Figs. 5c, 5d, 6c and $6 \mathrm{~d}$, which represent specimen microstructure after the specimens were treated by sharp shot peening conditions, $p=4$ bar, $\dot{m}=1.6 \mathrm{~kg} / \mathrm{min}$ and $p=$ 8 bar, $\dot{m}=1.5 \mathrm{~kg} / \mathrm{min}$. Various defects, such as surface damage, can be detected. They indicate that the selected shot peening conditions were inadequate.

The specimens subjected to lower working air pressure, i.e. 1.6 bar, reveal no noticeable surface or under surface defects that might reduce material longevity. Additional microhardness and residual stress measurements of the thin surface layer confirmed the treatment results related to dislocation density.

The extreme shot peening conditions also yielded fractures occurring because the critical level of the specimen's local cold deformation after the impact was exceeded. Surface defects and fractures in the shot-peened surface layer reduce material quality in terms of longevity and stability in dynamic loading of mechanical parts through local stress concentrations. As a result, the existing fractures may be enhanced during operation by the

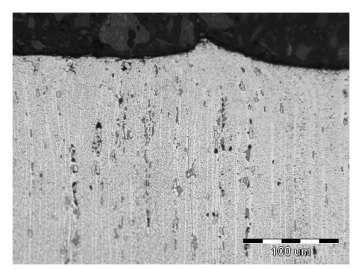

M 200:1

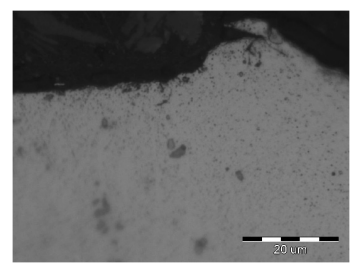

M 1000:1

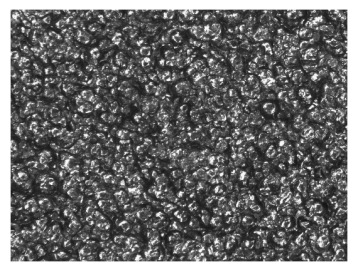

M 40:1

a) $p_{1}=1.6 \mathrm{bar}$,

$\dot{m}=1.0 \mathrm{~kg} / \mathrm{min}$,

$R_{z}=29.97 \mu \mathrm{m}$,

$R_{a}=6.03 \mu \mathrm{m}$

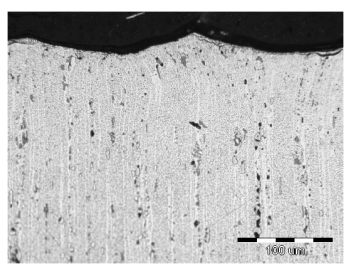

M 200:1

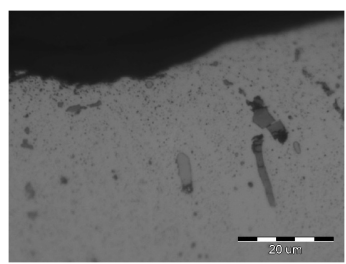

M 1000:1

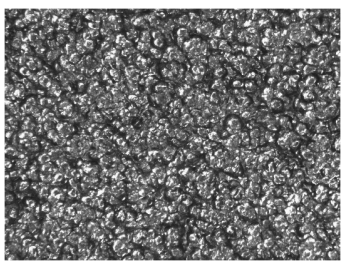

M 40:1

b) $p_{2}=1.6 \mathrm{bar}$, $\dot{m}=1.6 \mathrm{~kg} / \mathrm{min}$, $R_{z}=25.91 \mu \mathrm{m}$, $R_{a}=5.19 \mu \mathrm{m}$

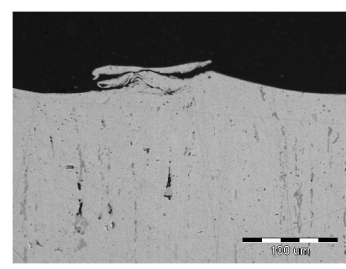

M 200:1

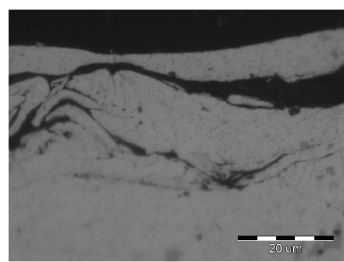

M 1000:1

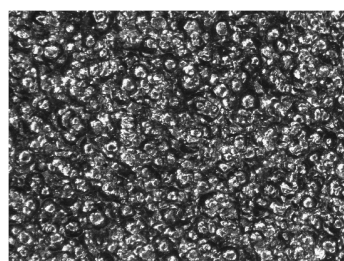

M 40:1

c) $p_{3}=4 \mathrm{bar}$,

$\dot{m}=1.5 \mathrm{~kg} / \mathrm{min}$,

$R_{z}=39.81 \mu \mathrm{m}$,

$R_{a}=8.31 \mu \mathrm{m}$

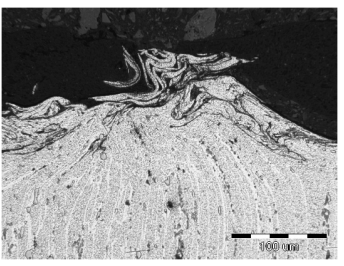

M 200:1

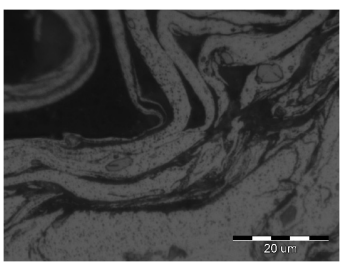

M 1000:1

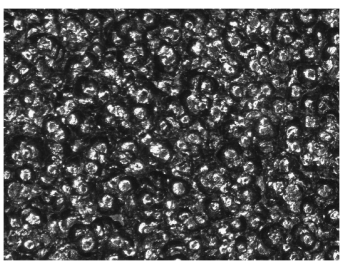

M 40:1

d) $p_{4}=8$ bar,

$\dot{m}=1.6 \mathrm{~kg} / \mathrm{min}$,

$R_{z}=55.89 \mu \mathrm{m}$,

$R_{a}=12.13 \mu \mathrm{m}$

Fig. 5. Microstructure of aluminium alloy after shot peening treatment; a) $2007 / 1$, b) $2007 / 8$, c) $2007 / 9$, d) $2007 / 13$ 


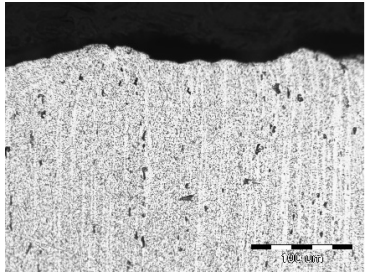

M 200:1

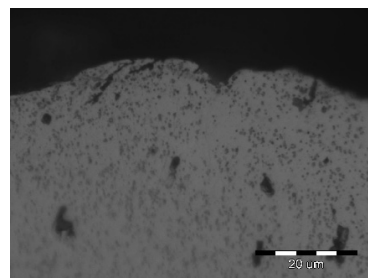

M 1000:1

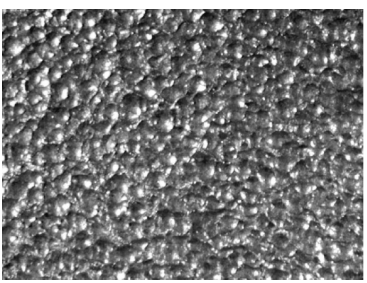

M 40:1

a) $p_{1}=1.6 \mathrm{bar}$, $\dot{m}=1.0 \mathrm{~kg} / \mathrm{min}$, $R_{z}=33.41 \mu \mathrm{m}$, $R_{a}=6.82 \mu \mathrm{m}$

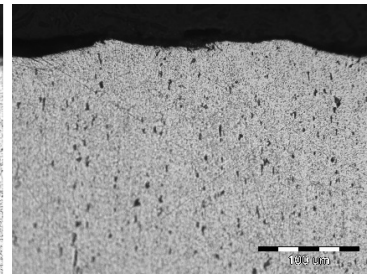

M 200:1

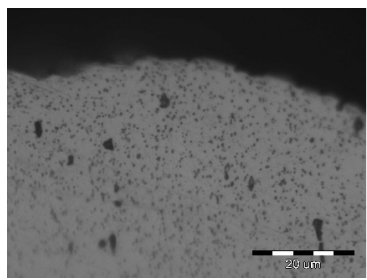

M 1000:1

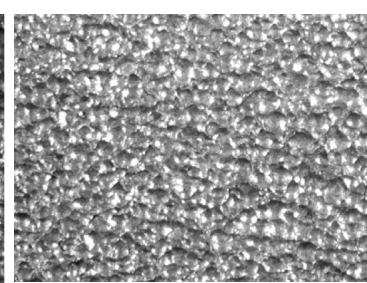

M 40:1

b) $p_{2}=1.6 \mathrm{bar}$, $\dot{m}=1.6 \mathrm{~kg} / \mathrm{min}$, $R_{z}=31.75 \mu \mathrm{m}$, $R_{a}=6.38 \mu \mathrm{m}$

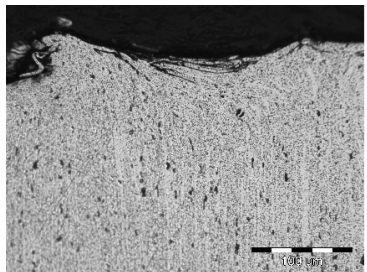

M 200:1

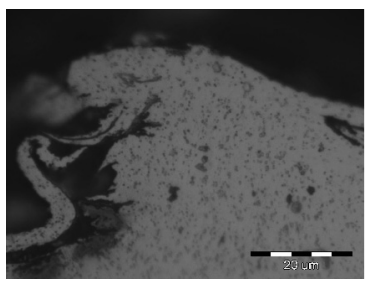

M 1000:1

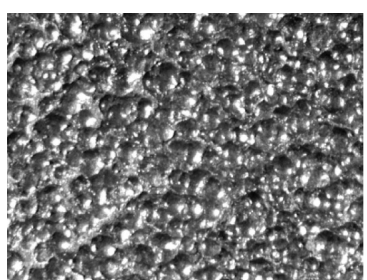

M 40:1

c) $p_{3}=4$ bar,

$\dot{m}=1.5 \mathrm{~kg} / \mathrm{min}$,

$R_{z}=47.98 \mu \mathrm{m}$,

$R_{a}=10.33 \mu \mathrm{m}$

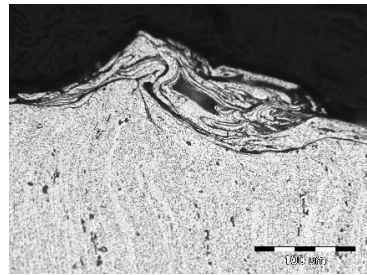

M 200:1

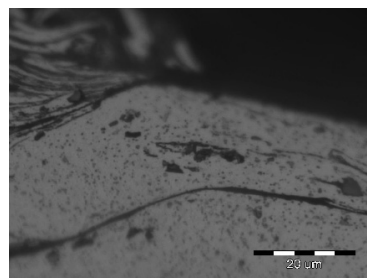

M 1000:1

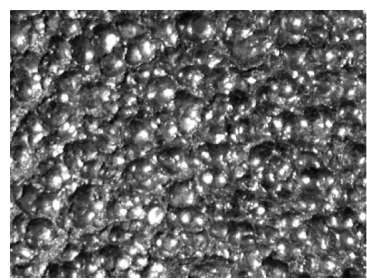

M 40:1

d) $p_{4}=8$ bar, $\dot{m}=1.6 \mathrm{~kg} / \mathrm{min}$, $R_{z}=65.73 \mu \mathrm{m}$, $R_{a}=13.93 \mu \mathrm{m}$

Fig. 6. Microstructure of aluminium alloy after shot peening treatment; a) $6082 / 1$, b) $6082 / 8$, c) $6082 / 9$, d) $6082 / 13$

stress-concentration factor causing a collapse of the mechanical part.

\subsection{Microhardness}

Microhardness measurement was performed in the adequately prepared specimen cross-sections. The specimens were cut in fourths, inserted into bakelite, ground, polished and etched to ensure a smooth surface and a clearly visible microstructure and to separate the indentations in order to determine microhardness profiles. The primary aim of the research was to establish a correlation between the microstructure and indentation size or the microhardnesses of individual specimens subjected to different shot peening conditions.

After the specimens were thus prepared, a reliable microhardness profile of the thin surface layer was determined based on the selected microhardness measurement method given in Fig. 7. The microhardness of the specimens was measured only by examining the treated layer where the material hardness is greater than the hardness of the alloy in its primary phase. As reference, a distance of $25 \mu \mathrm{m}$ between individual indentations was selected following a line $18^{\circ}$ to the surface. In this way, a sufficient number of measurements were performed to allow for an accurate presentation of microhardness profile. In measuring microhardness perpendicular to the line of the treated surface, the measurements were performed horizontally with $25 \mu \mathrm{m}$ gaps while the specimen was moved vertically in three diagonal lines $75 \mu \mathrm{m}$ apart. This procedure prevents the results of the microhardness measurements to be influenced by material hardening due to previous measurements. The selected microhardness 
measurement method was then repeated at three measuring positions indicated in Fig. 7 as I, II, and III. The measurements were performed in both cross-sections, 1 and 2. This makes up six microhardness measuring sets performed at different measuring points in each specimen.

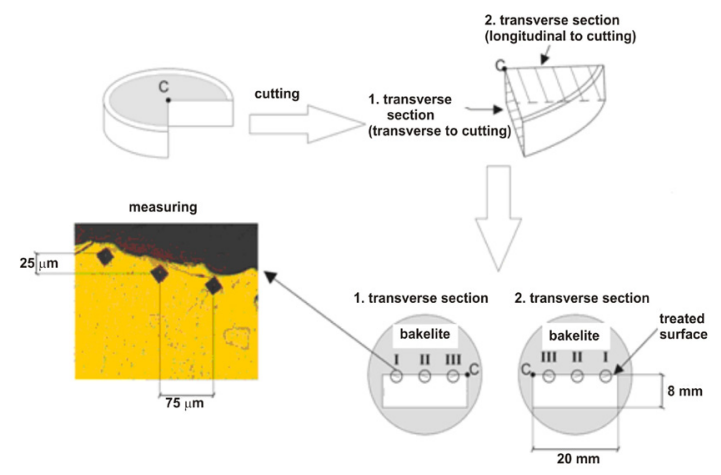

Fig. 7. Sample preparation for microhardness measuring

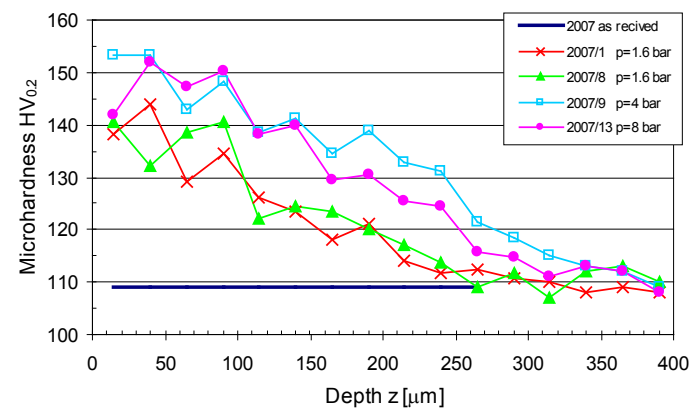

Fig. 8. Microhardness profiles for aluminium alloy ENAW 2007

Figs. 8 and 9 represent microhardness profiles in the surface layer for different parameters applied to the treated specimens of the ENAW 2007 and ENAW 6082 alloys respectively. The microhardness profile is a good indicator of the hardened surface layer which significantly influences the operation of mechanical parts in dynamic loading. A higher degree of cold plastic deformation in the surface layer of the material indicates an increased density of dislocations, influencing, together with the density and size of the precipitates, the properties of the surface layer.

Fig. 8 shows the microhardness profiles of the ENAW 2007 alloy, measured in the specimens treated with the working air pressure of 1.6, 4, and 8 bar. The microhardness profiles predictably mildly descent in all cases. In the specimens treated with $1.6 \mathrm{bar}$, the surface microhardness values and microhardness in-depth profile are lower than those in the specimens treated with a higher air pressure. There is a substantial difference in the hardness achieved, amounting up to 20 $\mathrm{HV}_{0.2}$, i.e. $20 \%$ of the hardness of the material in its primary phase. Based on the microhardness profiles, hardness depth can be estimated for individual surface treatment parameters. Hardness depth in the specimens treated with the working air pressure of 1.6 bar was $260 \mu \mathrm{m}$, while in the specimens treated with a higher air pressure its values were cosiderably higher, even up to 390 $\mu \mathrm{m}$. The following can be concluded from the measurement of the microhardness profiles:

- The profiles of the measured microhardnesses are very similar and differ only in hardness depth and absolute values.

- Important differences are found in microhardness values for specimens treated with air pressure lower than 1.6 bar and those treated with higher air pressures, 4 or 8 bar.

- The depth of the hardness achieved also depends on treatment parameters, amounting to about $260 \mu \mathrm{m}$ for lower and to about 390 $\mu \mathrm{m}$ for higher air pressure values.

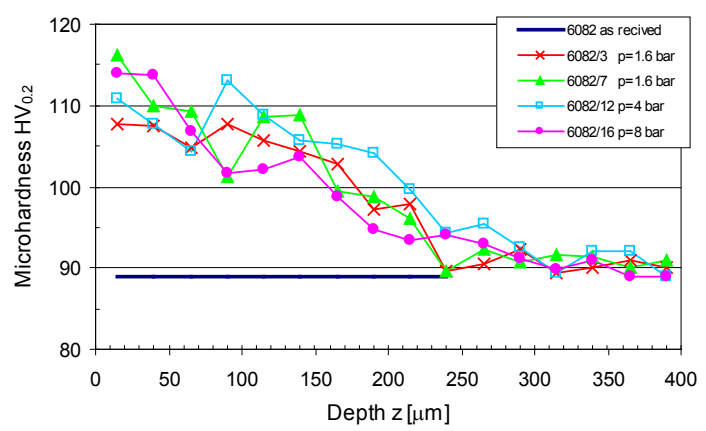

Fig. 9. Microhardness profiles for aluminium alloy ENAW 6082

Fig. 9 shows the microhardness profiles in individual ENAW 6082 specimens treated with the same parameters as the ENAW 2007 specimens. Based on individual microhardness measurements in the specimens treated with the intensities of $I=0.53 \mathrm{mmA}$ and $I=0.7 \mathrm{mmA}$, a $30 \%$ increase in microhardness is found after shot peening compared to the average hardness values of non-hardened specimens. An important factor is a falling trend of microhardness values in 
the thin surface layer. In addition to air pressure, nozzle speed and particle mass flow also show a significant influence on microhardness profiles or microhardness profile in-depth gradient.

The microhardness profile of the treated surface layer is indicative of the degree and depth of material hardening that influence residual stress size and profile. The achieved residual stresses improve the fatigue strength of the material in dynamic loading of mechanical parts, which prolongs its life cycle. The soft-state hardness of the ENAW 6082 alloy is $89 \mathrm{HV}_{0.2}$ but is increased to $111 \mathrm{HV}_{0.2}$, i.e. by $25 \%$, when subjected to shot peening with the working air pressure 4 bar and a mass flow of $1.6 \mathrm{~kg} / \mathrm{min}$. Based on the microhardness profiles, the depth of the hardened layer was determined in relation to the hardening conditions. The results reveal a hardening depth of $240 \mu \mathrm{m}$ in shot peening with a pressure of $1.6 \mathrm{bar}$ and a depth of $390 \mu \mathrm{m}$ for higher pressure values.

\subsection{Residual Stresses}

The residual stresses were measured by applying the ASTM standard-based hole-drilling method of stress relaxation [17] and [18]. The measurements were performed by using the Vishay RS 200 device with a pneumatic turbine for high-speed drilling. Due to the increased roughness of the specimen surface, the preparation of the specimens and the setting of the resistancemeasuring rosette needed to be carried out very carefully for each residual stress measurement. The CEA-06-062-UM resistance-measuring rosette manufactured by Measurements Group Inc. was used to measure the deformations. The enhanced measuring signal was recorded by using the AT-MIO-16XE-50 data acquisition card and the National Instruments Lab VIEW 4.0 program. The results were processed with the H-DRILL program and the residual stress values were calculated using the integral method, which delivers a separate residual stress estimation for each step of the in-depth drilling process. The graphical representation of the results was given in Microsoft Excel.

Fig. 10 shows the profiles of the minimal values of the main residual stresses in the specimen surfaces of the ENAW 2007 alloy treated with hard steel particles with different air pressure values. By measuring the deformations in each step of the resistance measuring, the necessary data was obtained to calculate the size of the main deformations and the main residual stresses.

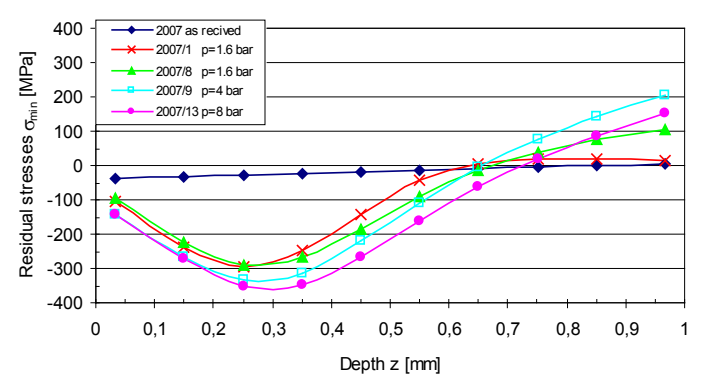

Fig. 10. Residual stress profiles for aluminium alloy ENAW 2007

The values of the residual stresses in the starting state of the ENAW 2007 specimen, which occur in the mechanical specimen preparation (i.e. cutting of specimens), are minimal. The minimal residual stresses in the specimen surface even amount to about $-50 \mathrm{MPa}$. In the 2007/1 and 2007/8 specimens, treated with lower Almen values, 10 and $12 \mathrm{~A}$, a very similar residual stress profile can be found. The residual stresses achieved in these specimens are approximately $-295 \mathrm{MPa}$, reaching a depth of about $250 \mu \mathrm{m}$. Likewise, the specimen marked 2007/9, which was treated with a working air pressure of 4 bar and a mass flow of $1.6 \mathrm{~kg} / \mathrm{min}$, a residual stress of $-340 \mathrm{MPa}$ was calculated for the depth of $270 \mu \mathrm{m}$. The 2007/13 specimen, which was subjected to the most severe conditions of working air pressure of 8 bar, only a minor increase in compressive stress value was determined, i.e. $-362 \mathrm{MPa}$, at the depth of about $290 \mu \mathrm{m}$.

However, regardless of any shot peening parameters, the compressive residual stresses in the specimens are directed towards the tensile area with a gradient similar to the one in the surface, i.e. $1.05 \mathrm{MPa} / \mu \mathrm{m}$. The transition from the compressive to the tensile area occurs between 650 and $700 \mu \mathrm{m}$ almost independently of the treatment conditions, except in the 2007/1 specimen, treated with the least severe conditions, where the residual stresses, having reached the tensile area, remain almost constant at $20 \mathrm{MPa}$ all the way through to the measuring depth of 1000 $\mu \mathrm{m}$. 


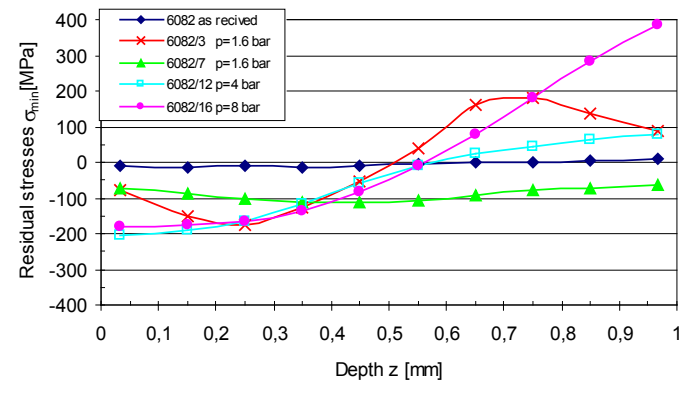

Fig. 11. Residual stress profiles for aluminium alloy ENAW 6082

Fig. 11 shows the profiles of the minimal values of the main residual stresses in the EN AW 6082 aluminium alloy. The compressive residual stresses in the specimen's starting state after the cutting were very low, i.e. $-15 \mathrm{MPa}$, reaching to a depth of $150 \mu \mathrm{m}$, and achieving the value of $10 \mathrm{MPa}$ at $950 \mu \mathrm{m}$. The lowest residual stress value is found in the $6082 / 7$ specimen, treated with a mass flow of $1.5 \mathrm{~kg} / \mathrm{min}$ and a working air pressure of 1.6 bar. The main residual stress which was calculated is of a compressive nature with the highest value of $-115 \mathrm{MPa}$ at $450 \mu \mathrm{m}$ that remains practically constant all through to 550 $\mu \mathrm{m}$. At greater depths, the residual stress profiles gradually turn towards the tensile area, except in the $6082 / 7$ specimen, where it remains within the compressive area all through to the measuring limit of $1000 \mu \mathrm{m}$.

The 6082/3 specimen, treated with the lowest Almen intensity of $10 \mathrm{~A}$, shows a greater residual stress value compared to the former, which amounts to $-167 \mathrm{MPa}$ at a depth of 250 $\mu \mathrm{m}$. After having reached the highest value, the residual stress profiles in the surface layer of this specimen are always directed towards the tensile area which they reach at a depth of $500 \mu \mathrm{m}$. The achieved residual stresses in the specimens treated with the highest working air pressures are obtained with similar residual stress profiles, amounting to $-203 \mathrm{MPa}$ in the $6082 / 12$ specimen and to about $-180 \mathrm{MPa}$ in the $6082 / 16$ specimen. In shot peening of the specimen surface with the highest air pressure, the maximum residual stress value is obtained immediately below the surface where the first measurement was performed at a depth of $33 \mu \mathrm{m}$. In both specimens subjected to the most severe conditions the tensile area is reached at about $550 \mu \mathrm{m}$.

\section{CONCLUSIONS}

To ensure the optimal properties of the surface layer hardened by cold deformation, the relevant parameters need to be reconciled, including the working air pressure that provides the necessary kinetic energy of the particle's impact with the specimen surface. By applying the shot peening technique, a very uniform hardening of the entire specimen surface is guaranteed with the aim of improving the fatigue strength of the material required for the operation of mechanical parts in dynamic loading. Shot peening parameters optimization allows to control the size and the profiles of residual stresses, i.e. microhardness. Therein lies the importance of research on the influence of the surface shot peening parameters in different materials [19].

Based on the performed microhardness and residual stress measurements, the following can be confirmed:

- The maximum values of the minimal compressive residual stresses in the ENAW 2007 alloy are $-362 \mathrm{MPa}$ at a depth of 290 $\mu \mathrm{m}$ and $-167 \mathrm{MPa}$ at a depth of $250 \mu \mathrm{m}$ in the ENAW 6082 alloy;

- In the treatment of both alloys, the values of the compressive residual stresses obtained in the surface layer were lower than the maximum values and amount to about 100 $\mathrm{MPa}$. A very small residual stress gradient confirms an immensely favourable effect of the surface treatment process. In relation to the yield stress of both alloys, which is about $250 \mathrm{MPa}$, the obtained compressive residual stress value means a substantially increased fatigue strength of the material;

- The macro- and microscopic surface examination revealed that lower air pressure values should be selected with the same particle mass flow. The results of the research confirmed that by applying the particles' kinetic energy obtained with lower air pressure values, a defect-free surface is guaranteed along with a substantial fatigue strength of the material. On the other hand, the treatment of the surface with higher air pressure values results in surface defects which influence the occurrence or growth of 
surface cracks and may lead to a collapse of the material.

\section{REFERENCES}

[1] Rodopoulos, C.A., Curtis, S.A., de los Rios, E.R., SolisRomero, J. (2004). Optimisation of the fatigue resistance of 2024-T351 aluminium alloys by controlled shot peening-methodology, results and analysis. International Journal of Fatigue, vol. 26, no. 8 , p. 849-856.

[2] Sharp, P.K., Clark, G. (2003). The effect of peening on the fatigue life of 7050 aluminium alloy. TSP, vol. 16, no. 4.

[3] Shot Peening Applications, 9th Ed., Metal Improvement Company, 2005.

[4] George, P.M., Pillai, N., Shah, N. (2004). Optimization of shot peening parameters using Taguchi technique. Journal of Material Processing Technology, vol. 153154, p. 925-930.

[5] Benedetti, M., Bortolamedi, T., Fontanari, V., Frendo, F. (2004). Bending fatigue behaviour of differently shot peened $\mathrm{Al} 6082$ T5 alloy. International Journal of Fatigue, vol. 26, no. 8, p. 889-897.

[6] Sidhom, N., Laamouri, A., Fathallah, R., Braham, C., Lieurade, H.P. (2005). Fatigue strength improvement of 5083 H11 Alalloy T-welded joints by shot peening: experimental characterization and predictive approach. International Journal of Fatigue, vol. 27, p. 729-745.

[7] Sahaya Grinspan, A., Gnanamoorthy, R. (2006). Surface modification by oil jet peening in $\mathrm{Al}$ alloys AA6063-T6 and AA6061-T4: Residual stress and hardnes. Applied Surface Science, vol. 253. p. 989996.

[8] Wagner, L. (1999). Mechanical surface treatments on titanium, aluminum and magnesium alloys. Materials Science and Engineering, vol. A263, p. 210-216.

[9] Jaensson, B., Magnusson, L. (1987). An investigation into the influence on the fatigue strength of aluminium alloy parts of load spectrum base level and residual stresses induced by shot peening or straightening.
Proceedings of the 3 rd International Conference on Shot Peening, p. 423-430.

[10] Herzog, R., Zinn, W., Scholtes, B., Wohlfahrt, H. (1996). The Significance of almen intensity for the generation of shot peening residual stresses. Proceedings of the $6^{\text {th }}$ International Conference on Shot Peening, San Francisco.

[11] Guagliano, M. (2001). Relating Almen intensity to residual stresses induced by shot peening: a numerical approach. Journal of Material Processing Technology, vol. 110, no. 3, p. 277-286.

[12] Hong, T., Ooi, J.Y., Shaw, B. (2008). A numerical simulation to relate the shot peening parameters to the induced residual stresses. Engineering Failure Analysis, vol. 15, no. 8, p. 1097-1110.

[13] Kek, T., Grum, J. (2010). Influence of the graphite absorber during laser surface hardening. Strojniški vestnik - Journal of Mechanical Engineering, vol. 56, no. 2, p. 150-157.

[14] Trdan, U., Ocaña, J.L., Grum, J. (in press). Surface modification of aluminium alloys with laser shock processing. Strojniški vestnik - Journal of Mechanical Engineering, DOI:10.5545/sv-jme.2010.119.

[15] Zupanc, U., Grum, J. (in press). Surface integrity of shot peened of 7075-T651 aluminium alloy. Strojniški vestnik - Journal of Mechanical Engineering, DOI:10.5545/ sv-jme.2010.124.

[16] Grum, J. (2008). Surface integrity after shot peening applied to a precipitation hardened aluminium alloy. Metal Finishing News, vol. 9, no. 9, p. 54-56.

[17] Standard Test Method for Determining Residual Stresses by the Hole Drilling Strain Gage Method (1995). ASTM E 837-01, p. 694-703.

[18] Tech note TN 503-5 (1993). Measurement of Residual Stresses by the Hole-Drilling Strain Gage Method, Vishay Measurements Group.

[19] Schulze, V. (2005). Modern Mechanical Surface Treatment: States, Stability, Effects, WILEY-VCH Verlag Gmbh \& Co. KGaA, Weinheim. 